\title{
EDITORIAL
}

\section{MULTIPLICIDADE DA PSICOLOGIA BRASILEIRA}

\author{
Marilda Castelar*, Monica Ramos Daltro** \\ * Editora da Revista Psicologia Diversidade e Saúde. Professora da Escola Bahiana de Medicina e Saúde Pública. \\ E-mail: marildacastelar@bahiana.edu.br \\ ** Professora da Escola Bahiana de Medicina e Saúde Pública. E-mail: monicadaltro@bahiana.edu.br
}

\begin{abstract}
A psicologia, jovem profissão de 53 anos, ao longo de seu processo de consolidação identitária, vem sendo convocada a dar respostas ao que não é alcançado pelas ciências naturais ou pelas pedagogias adaptativas. Com este desafio, a psicologia no Brasil se inventa e reinventa a partir das suas práticas profissionais, investindo em suas múltiplas possibilidades de encontro com os sujeitos da complexidade.
\end{abstract}

Pensada como um campo, a psicologia está apresentada de forma miscigenada e plural, como definiu Arthur Arruda Leal Ferreira em 2010. Sustentada por uma história de referências da modernidade iluminista, tem pela natureza de seus objetos de estudo e intervenção a possibilidade de se abrir continuamente a múltiplos efeitos na contemporaneidade, reconhecendo a força da diversidade e seu compromisso com a redução das desigualdades sociais e com a garantia dos direitos humanos.

Não por acaso, a psicologia engendra-se de forma significativa no campo da saúde, especialmente no Sistema Único de Saúde (SUS), considerado um dos maiores empregadores de psicólogos do país, cujos princípios investem na promoção da saúde e no empoderamento de sujeitos e comunidades. Isso permite ao psicólogo (a) atuar em diferentes contextos de prática. Em contextos sustentados pela perspectiva patológica, caminha a passos largos oferecendo assistência hospitalar, como apresentada nos artigos referentes à revisão do corpo feminino a partir da mastectomia ou no fomento a tecnologias leves em saúde, como os contos de fada, apresentados como recurso terapêutico para crianças hospitalizadas. São práticas clínicas singularizadas pela existência do câncer.

A clínica entretanto amplia-se em muitas possibilidades que vão além do patológico, especialmente quando associadas às políticas públicas, como na experiência da Triagem Neonatal, que assume uma natureza, muitas vezes, preventiva junto a portadores de fenilcetanúria, como apresentado no artigo das professoras Isabela Queiroz e Milena Pondé. Novas formas de clínica, entretanto não excluem os modelos tradicionais de clínica como a psicanálise, mas também os convocam a novos olhares sobre as dimensões contemporâneas da cultura como no texto "O corpo como resposta a invocação materna".

Estudos desta natureza se contrapõem ao histórico e tradicional discurso sobre a clínica privatista e elitizada - presente na formação dos psicólogos. Esses novos espaços de pensar a psicologia desafiam a universidade a fomentar novas práticas educativas, como no artigo "A Clínica Ampliada no enfoque da Gestalt-Terapia: um relato de experiência em supervisão de 
estágio", mas também a emergência de outras formas de pensar ciência e métodos de pesquisa, como no texto sobre sociopoética e formação do pesquisador.

O conjunto destes olhares tem permitido a emergência de novas experiências e reflexões problematizadoras nos domínios de uma psicologia interdisciplinar, que atua em rede e acolhe o modo como cada sujeito, cada comunidade, se coloca no mundo. Ela também se mistura transformando e sendo transformada por outros campos de conhecimento que envolvam relações humanas na contemporaneidade, dimensões do campo do trabaIho, da educação, do sistema presidiário, da psicodinâmica do dependente de substâncias psicoativas e da assistência social. Assim, a psicologia está configurada como uma das mais importantes estratégias para pensar as causas, efeitos e possibilidades de mudança das enormes desigualdade sociais do Brasil contemporâneo.

Portanto, neste número da Revista Psicologia, Diversidade e Saúde, ela se apresenta como uma ciência e uma profissão que abriga grande diversidade de saberes, técnicas e práticas e que tem no cerne de seus processos a dimensão subjetiva da existência e modos de viver humano, afirmando a indissociabilidade entre somático, o psíquico e o social e o fazer em psicologia descrito a partir da promoção de saúde e qualidade de vida em diferentes contextos de prática. 